\title{
PERFORMANCE AND IMPROVEMENT OF ARS ULTRAWIDEBAND ANTENNA
}

\author{
R. Sambasiva Nayak ${ }^{l}$ \\ Dr.R.P. Singh ${ }^{2}$ \\ MIEEE, Research Scholar, \\ Vice-Chancellor \\ Dr.M. Satya Sai Ram $^{3}$ \\ Dr P.Karpagavalli ${ }^{4}$ \\ HOD \\ Assoc. Professor
}

\section{Department of ECE, Sri Satya Sai University of Technology and Medical Science, Sehore, Bhopal, Madhya \\ Pradesh, India. sambanayak@gmail.com, ramneeluphd@gmail.com. \\ 2. Sri Satya Sai University of Technology and Medical Science, Sehore, Bhopal, Madhya Pradesh, India prof.rpsingh@gmail.com}

\section{Department of ECE,Chalapathi Institute of Engineering and Technology, Chalapathi Nagar, Guntur, AP, India.msatyasairam@hotmail.com \\ 4.Department of ECE, Sri Satya Sai University of Technology and Medical Science, Sehore, Bhopal, Madhya Pradesh, India.}

\begin{abstract}
In this paper, a compact style and experimental study of microstrip-Line fed annular-ring formed (ARS) antenna is conferred. The antenna consists of two ARS that area unit diagonally connected to every different with a curving ring and a changed L-shaped ground plane. The antenna provides an extremist wide information measure with return loss, which apparently covers entire UWB band. Additionally, the antenna incorporates a considerably compact size. The measured and simulated results ensure the quality of the antenna for ultra-wideband applications.
\end{abstract}

\section{I.INTRODUCTION}

UltraWideband technology includes a big variety of applications in short-range high rate communications and microwave radar near-field imaging. As an example, microwave optics is employed for tissue imaging, microwave radar near-field imaging in fossil oil pipeline imaging to check the corrosion, and observance the submarine conditions of various objects. The important demand for pipeline review victimization microwave radar imaging is that antenna must be operated in fossil oil of insulator constant 2.5 , and also the size of the antenna ought to be as tiny as doable. Because the image resolution is directly proportional to the information measure of the heartbeat, all the imaging applications need wide information measure. Microstrip antenna with completely different shapes like octagonal-shaped, arc-shaped, M-shaped, ringshaped slot, polygon formed, M-shaped, triangular geometries has been projected for UltraWideband application. In, a C-shaped radiator with Associate in nursing inverted L-shaped coupled strip extending from the bottom plane is employed for information measure improvement, whereas coupling impact between the structures is employed to enhance the electric resistance matching. A plate like crossed monopole antenna and an oblong patch with Ushaped open-slot structure are rumored for the triangular geometries UltraWideband application. Doubled ramp-shape feeding techniques square measure used for increased information measure, and shorting pins square measure accustomed miniaturize the scale of the patches. A unique compact microstrip-fed UltraWideband step-slot antenna with a revolved patch for increased electric resistance information measure is incontestable in. All the antennas mentioned on top of square measure larger in size and offer a comparatively lower electric resistance information measure than the projected antenna style. Additional reduction of the antenna size would face a challenge because the sizes of those antennas are set by the longest electrical length of the surface currents at very cheap frequency. During this chapter, a miniaturized style is projected and investigated for broadband applications employing a microstrip-line fed annular-ring monopole radiator for line imaging. Within the projected style, an angular-ring formed diverging patch and defected ground plane is employed with an embedded curved stub within the feed-line to get increased information measure. The slotted ground-plane has 2 extended rectangular strips on each side that excites a further resonance at the lower frequency. The antenna is often simply matched into a pipeline while not obstructing the flow of the liquids. The antenna is additionally able to give seamless operation in fossil oil.

\section{II.DESIGN STRATEGY}

Figure 1 show a schematic configuration of the proposed geometry which is fed by a $2.4 \mathrm{~mm}$ wide microstrip line. The antenna is fabricated on an epoxy FR4 dielectric substrate (loss tangent, $\tan \delta=0.02$, relative permittivity, $\varepsilon r=4.4$ ) with very small dimensions of $15 \times 12 \times 1.6 \mathrm{~mm} 3$. The radiator consists of two annular-rings that are printed one over the other along with a rectangular strip of width Wf and length Lp2.

Table.1: Comparison of the Proposed Antenna with Other Reported Antennas

\begin{tabular}{|l|l|l|}
\hline Reference & Size & Operating \\
\hline $\mathbf{8}$ & $70 \times 60$ & $2.5-18$ \\
\hline $\mathbf{3}$ & $30 \times 30$ & $3.02-13.27$ \\
\hline $\mathbf{7}$ & $36 \times 36$ & $2.38-12.40$ \\
\hline $\mathbf{6}$ & $80 \times 80$ & $3-12$ \\
\hline $\mathbf{5}$ & $25 \times 23$ & $2.71-12.61$ \\
\hline $\mathbf{9}$ & $23 \times \mathbf{4 1}$ & $2.3-20$ \\
\hline $\mathbf{1 0}$ & $30 \times 30$ & $3-12$ \\
\hline $\mathbf{4}$ & $25 \times \mathbf{4 0}$ & $3.1-5.15$ \\
\hline $\mathbf{1}$ & $20 \times 20$ & $3.1-10.6$ \\
\hline $\mathbf{2}$ & $24.5 \times 24.5$ & $2.95-12.1$ \\
\hline Proposed & $\mathbf{1 5} \times \mathbf{1 2}$ & $\mathbf{3 . 0}-\mathbf{2 5}$ \\
\hline
\end{tabular}




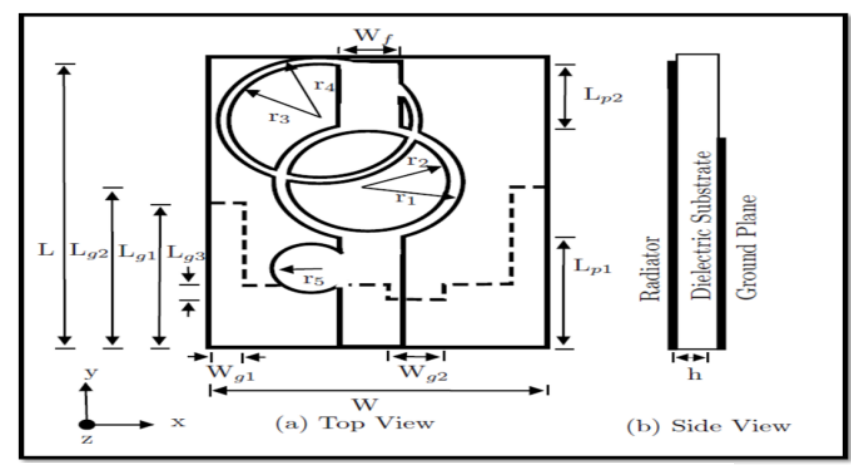

Figure 1: Schematic Configuration of the Proposed Prototype

The feed is modified by attaching a semicircular stub of $\mathrm{r} 5$ to provide $50 \Omega$ feed and to improve impedance matching. The slotted ground plane of the proposed antenna is printed on the other side of the dielectric substrate to improve impedance matching at the lower middle band. Further, two rectangular strips of lengths $\operatorname{Lg} 1$ and $\operatorname{Lg} 2$ of width $\mathrm{Wg} 1$ are connected at the edges of the ground plane to excite lower frequency band. It is clearly observed from Table 1 that the proposed antenna has the smallest size with enhanced bandwidth from the above-reported designs.

Table 2: Design Parameters of the Proposed Antenna shown in Fig. 1

\begin{tabular}{|c|c|c|c|c|c|c|c|}
\hline Parameters & ${ }^{\mathrm{L}} \mathbf{p} 1$ & ${ }^{\mathbf{L}} \mathbf{p}$ & ${ }^{\mathrm{w}_{\mathbf{f}}}$ & ${ }^{\mathrm{r}} \mathbf{1}$ & ${ }^{\mathrm{r}} \mathbf{2}$ & ${ }^{\mathbf{r}_{3}}$ & ${ }^{\mathbf{r}_{4}}$ \\
\hline Unit(mm) & 4.53 & 4.28 & 2.4 & 3.2 & 2.8 & 3.2 & 3.5 \\
\hline Parameters & ${ }^{\mathrm{W}} \mathrm{g} 1$ & ${ }^{\mathrm{W}} \mathrm{g} 2$ & ${ }^{\mathrm{L}} \mathrm{g} 3$ & ${ }^{\mathrm{L}} \mathrm{g} 1$ & ${ }^{\mathrm{L}} \mathrm{g}$ & $\mathrm{r}_{5}$ & $\mathrm{~W}$ \\
\hline Unit (mm) & 1.5 & 1.5 & 1 & 7.0 & 7.5 & 1.3 & 12 \\
\hline
\end{tabular}

The antenna style was enforced in 3 steps, as incontestable in Fig. 5.2. The 1st step involves a construction of the feed-line with an easy rounded formed patch; the second step is changed by attaching a curving conductor to the feed line, and also the final step involves making associate other rounded-ring on a top side of the annular patch. The come loss responses of the antenna altogether 3 steps area unit represented in Fig. 2. Therefore, the projected antenna provides an UltraWideband with a usable incomplete information measure of over $157 \% \quad(3-25 \mathrm{GHz})$. The parameters of the projected pure mathematics area unit optimized to realize a miniaturized style, and optimized dimensions area unit listed in Table.2.

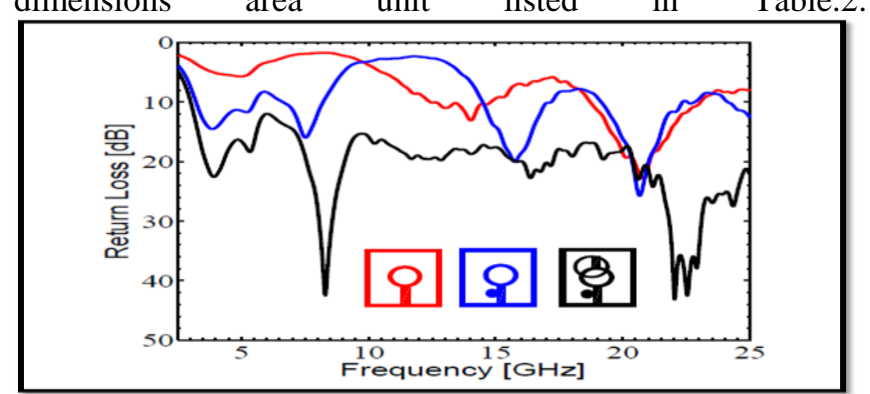

Figure.2: Simulated Return Loss against Frequency for Three Steps that are used for designing the antenna

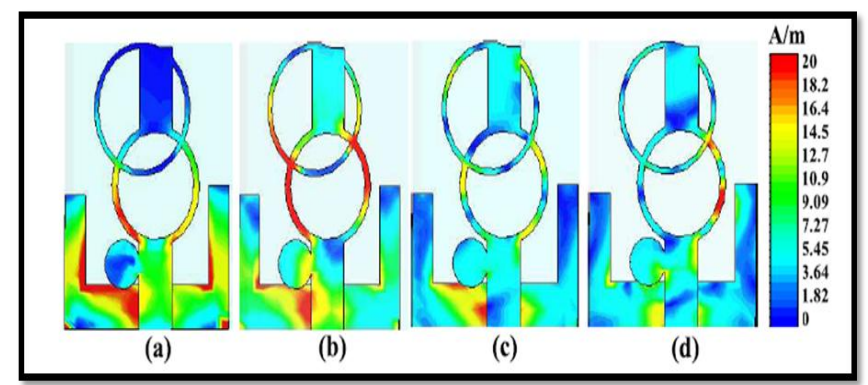

Figure.3: simulated surface current distribution of the proposed antenna at (a) $3.9 \mathrm{GHz}$ (b) $6 \mathrm{GHz}$ (c) $16 \mathrm{GHz}$ and (d) $22 \mathrm{GHz}$ frequencies

The various simulated current densities square measure planned in fig .3 to know the improved broadband behavior of the antenna. Fig. 3(a) depicts that the surface current is principally distributed over the whole ground plane and also the lower rounded ring of the patch. It clearly indicates that the lower band is worked up because of each the oblong strips hooked up to the bottom plane and a lower rounded ring. The surface currents square measure primarily distributed over the bottom plane and central elements of the radiator for the frequency around 6 gigahertz. For middle frequencies around sixteen gigahertz, this is focused around rounded rings of the patch and feed-line as shown in Fig.3(c). Finally, Fig. 3(d) shows that this is distributed over entire patch and ground plane.

\section{III.PARAMETRIC STUDY}

Simulated return loss curves for various parameters of the antenna are discussed in order to show the effectiveness of the designed antenna. Fig.4 depicts the variation of the outer radius ( $\mathrm{r} 1$ ) of the annular ring with frequency. It is observed that for the outer radius $\mathrm{r} 1=3.2 \mathrm{~mm}$, the antenna shows enhanced impedance bandwidth from 3-25 GHz. Therefore, r1 is used to enhance impedance bandwidth and improve impedance mismatch that mainly occurs at the middle (7-13 $\mathrm{GHz}$ ) and higher frequency bands. Figure .3: Simulated Surface Current Distribution of the Proposed Antenna at (a) $3.9 \mathrm{GHz}$ (b) $6 \mathrm{GHz}$ (c) $16 \mathrm{GHz}$ and (d) $22 \mathrm{GHz}$ Frequencies The various simulated current densities are plotted in Fig.3 to understand the enhanced

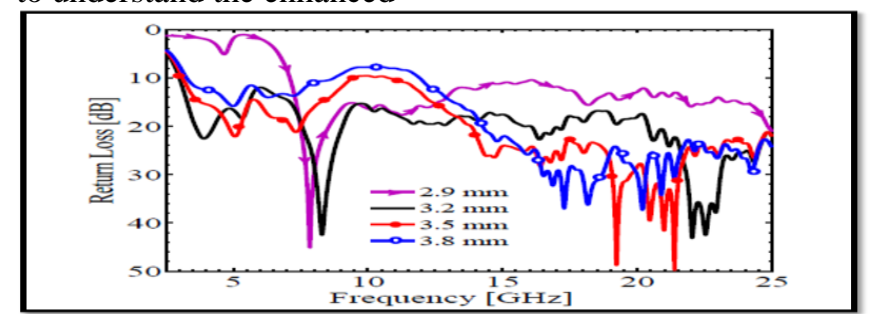

Figure.4:Simulated Return Loss against Frequency of the Proposed Antenna with Radius rl

Fig. 5 depicts the return loss curve of the parameter (r5), i.e., the radius of the semicircular stub attached to the feed-line with frequency. As the value of $\mathrm{r} 5$ increases from $0.9 \mathrm{~mm}$ to $1.3 \mathrm{~mm}$, impedance matching greatly improves. It is found that return loss of the antenna remains below $10 \mathrm{~dB}$ for $\mathrm{r} 5=$ $1.3 \mathrm{~mm}$. Further increment in the value of $\mathrm{r} 5$ degrades the performance of the antenna. Therefore, at $\mathrm{r} 5=1.3 \mathrm{~mm}$ the antenna shows enhanced impedance bandwidth from 3-25 $\mathrm{GHz}$. 


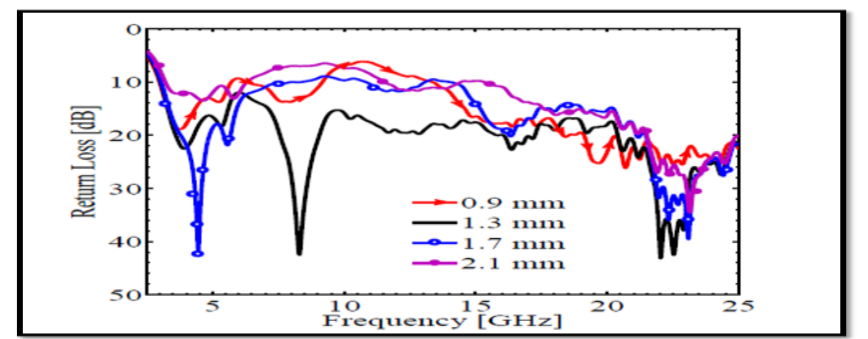

Figure 5:Simulated Return Loss against Frequency of the Proposed Antenna with Radius r5

In the proposed antenna design, the ground plane parameters significantly control the impedance bandwidth of the antenna. In order to get the best performance, various simulations were carried out. The rectangular strips extended on both sides of ground plane excite the first resonance in the proposed antenna. Fig. 6 shows the return loss curves of the proposed antenna for various ground strip lengths $(\operatorname{Lg} 1)$ with frequency. It is observed that for length $\operatorname{Lg} 1=7 \mathrm{~mm}$, the antenna shows enhanced impedance bandwidth from 3$25 \mathrm{GHz}$. Therefore, $\operatorname{Lg} 1$ is used to improve impedance matching at the lower and middle-frequency bands. The width Wg1 of the rectangular strip also affects the performance of the antenna. Fig. 7 shows the simulated return loss curve of the proposed antenna for various ground strip widths Wg1 with frequency.

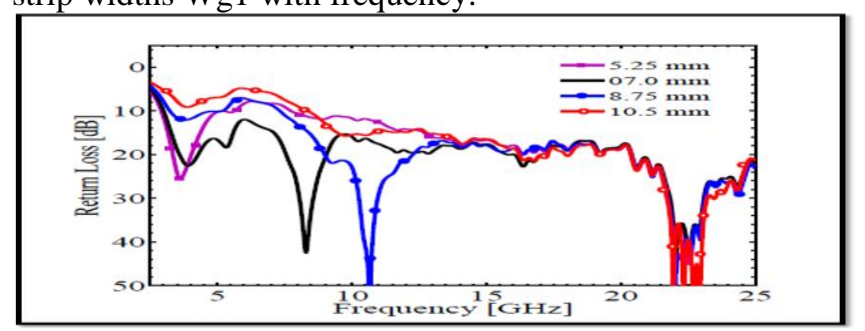

Figure6:Simulated Return Loss against Frequency of the Proposed Antenna with Length Lg1

As the value of $\mathrm{Wg} 1$ increases from $0.3 \mathrm{~mm}$ to $2.1 \mathrm{~mm}$, the impedance matching mainly at lower frequency band improves. Therefore, at $\mathrm{Wg} 1=1.5 \mathrm{~mm}$ the antenna shows enhanced impedance bandwidth from 3-25 GHz.

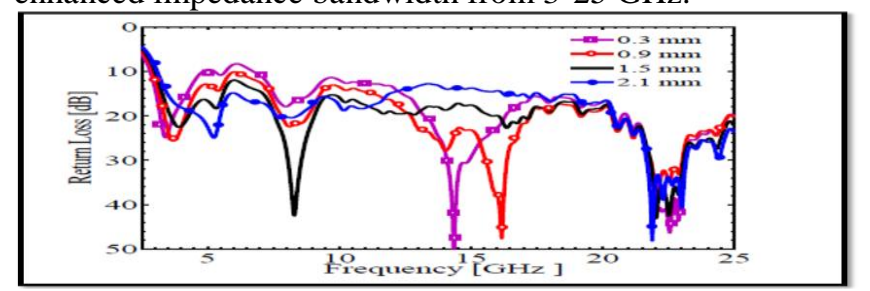

Figure.7:Simulated Return Loss against Frequency of the Proposed Antenna with Width Wgl

ANALYSIS

The pulse handling capability in conjunction with at the fidelity issue calculation of the projected antenna is measured by time-domain analysis victimization Central Standard Time MWS. These studies area unit distributed by inserting 2 antennas within the far-field region. The transmitter is worked up by a Gaussian signal that complies with the FCC indoor and outside power spectrum mask. Fig. 8 shows the input and received signals within the farfield region. The low-distortion time-domain performance of the miniaturized antenna is additionally confirmed by scheming the fidelity issue. Fidelity issue is employed to live the degree of similarity or correlation between the transmitted and received pulses. The fidelity factors within the case of face-to-face and side-by-side area unit obtained as seventy three and sixty one, severally.

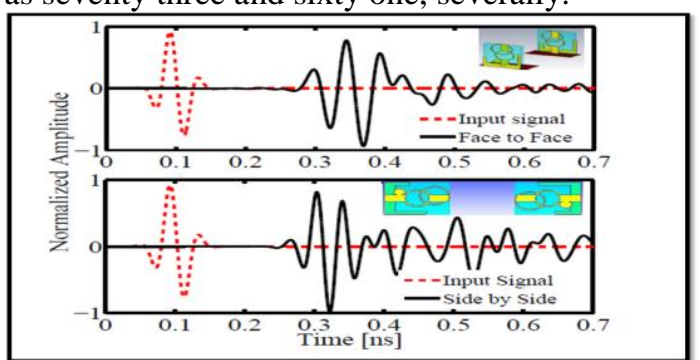

Figure.8: input and received pulse in different orientations of proposed antenna

The group delay is another parameter in time domain analysis, which shows the distortion of the transmitted pulses in the wideband communication. Therefore, the group delay shall be almost constant in the entire operating band for a good pulse transmission. It is seen from Fig. 9 that the group delay of the proposed antenna remains constant as it shows a variation of 1 ns only. The group delay characteristics discussed above demonstrate that the proposed antennas exhibit phase linearity at desired operating frequencies. It is found, from the aforesaid parametric studies in the time domain, that the antenna has a good pulse handling capability in the entire operating frequency band.

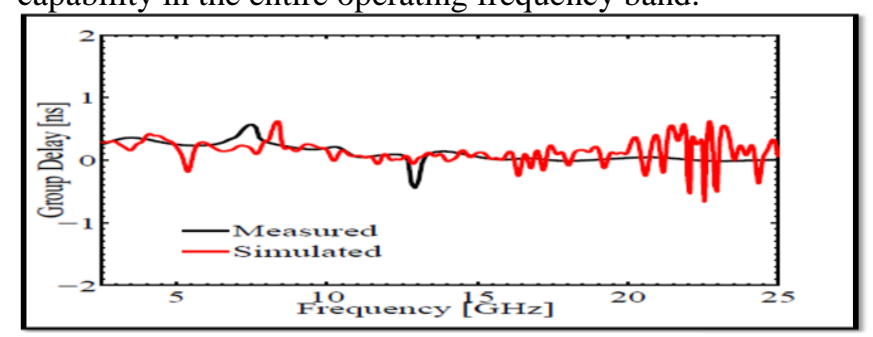

Figure.9: Group Delay of the Proposed Antenna

RESULTS\&DISCUSSION

After optimization, the proposed antenna was fabricated with the MITS Eleven Lab PCB machine. Then to validate the simulated results, the antenna return loss is measured by submerging the antenna in diesel using the Agilent N5230A vector network analyzer. Diesel has the same dielectric constant as crude oil [158]. Fig. 5.10 shows the variations of the return loss with frequency for the proposed enhanced bandwidth antenna. It is found that the antenna shows an enhanced wide bandwidth for return loss $<10 \mathrm{~dB}$ of $22 \mathrm{GHz}$ (from 3-25 GHz). The measured result shows good agreement with simulated one Some deviation in result may be due to fabrication tolerance or measurement as it is carried out in the scattering environment.

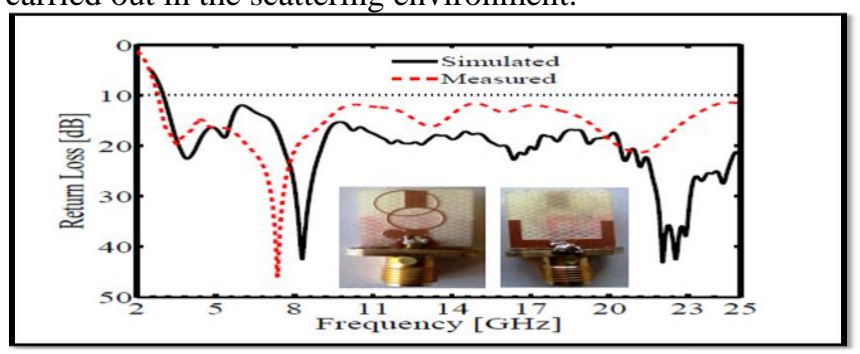

Figure 10: Return Loss Variation with Frequency

The variations of the gain and the radiation efficiency with 
the frequency of the proposed antenna are shown in Fig. 11. It is evident that the antenna shows a good radiation efficiency for the entire band of operation within $75 \%$ to 90\%. It is also observed in Fig. 11 that the gain of the proposed antenna varies from $2.8 \mathrm{~dB}$ to $5.8 \mathrm{~dB}$. Thus, the gain of the proposed antenna remains stable, and its low value is due to the very compact size of the antenna.

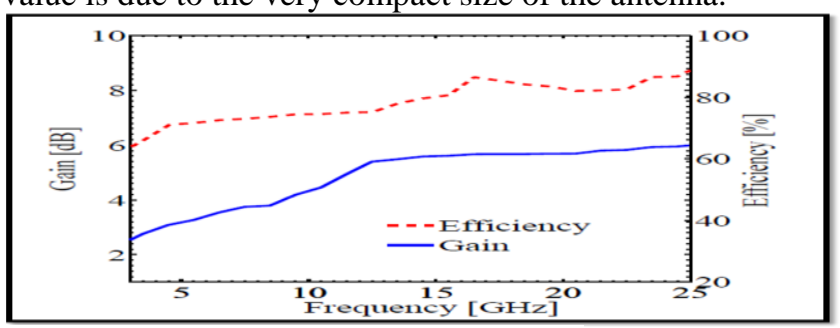

Figure 11: Gain and Radiation Efficiency

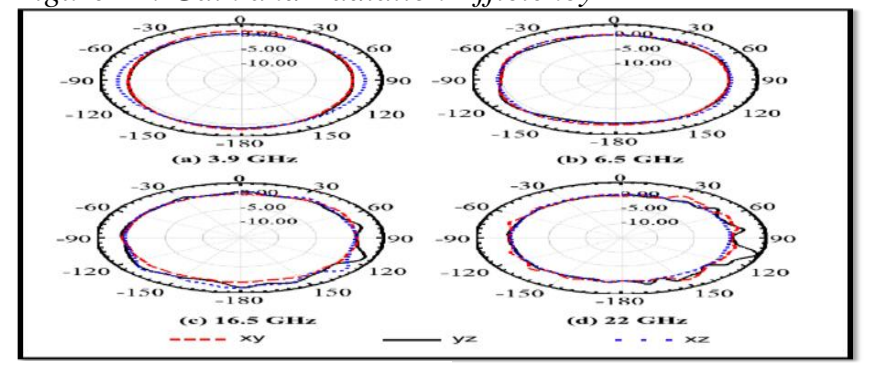

Figure 12: RPs at Various Freq

Figure 12 shows the measured radiation patterns in the xy-, yz- and xz- planes at various sampling frequencies $(3.9,6.5$, 16.5 and $22 \mathrm{GHz}$ ). It is seen that the radiation pattern is like a monopole antenna pattern at the lower frequency side (3 $\mathrm{GHz}$ ). At higher frequencies, the radiation is due to the higher order modes which are responsible for a splitting of the radiation lobe.

\section{CONCLUSIONS}

In this section, a novel miniaturized design of UltraWideband monopole antenna for enhanced wide bandwidth performance is successfully presented. The designed antenna offers an impedance bandwidth of $22 \mathrm{GHz}$ with a good impedance matching and stable radiation pattern. As the size of the antenna is very small, it is a potential candidate for pipeline inspection using radar imaging. Moreover, the main application of UltraWideband antenna is in indoor surroundings where multipath propagation leads to detrimental Inter-Symbol Interference (ISI). In the next chapter, therefore, multiple or multipleinput and multiple-output antennas will be designed in order to turn this drawback into an advantage.

\section{REFERENCES}

[1] S. Ghosh, "Design of planar crossed monopole antenna for UltraWideband communication," IEEE Antenna and Wireless Propagation Letters, vol. 10, pp. 548-551, 2011.

[2] W. Liu, Y. Yin, W. Xu, and S. Zuo, "Compact open-slot antenna with bandwidth enhancement," IEEE Antenna and Wireless Propagation Letters, pp. 850-853, 2011.

[3] J. H. Lu and C. H. Yeh, "Planar broadband Arc-Shaped mono pole antenna for UWB system," IEEE Transactions on Antennas and Propagation, vol. 60, pp. 3091-3095, July 2012.

[4] G. H. Kim and T. Y. Yun, "Compact ultrawideband monopole antenna with an inverted-L-shaped coupled strip," IEEE Antenna and Wireless Propagation Letters, vol. 12,1291-1294, 2013.
[5] K. Gautam, R. Chandel, and B. K. Kanaujia, "A CPW-fed hexagonal-shape monopole-like UWB antenna," Microwave and Optical Technology Letters, pp. 2624- 2628, November 2013.

[6] M. Gallo, E. A. Daviu, M. F. Bataller, M. Bozzetti, J. M. M. G. Pardo, and L. J. Llace, "A broadband pattern diversity annular slot antenna," IEEE Transactions on Antennas and Propagation, vol. 60, pp. 1596-1600, March 2012.

[7] M. K. Shrivastava, A. K. Gautam, and B. K. Kanaujia, "An M-shaped monopole like slot UWB antenna," Microwave and Optical Technology Letters, vol. 56, pp. 127-131, Jan 2014.

[8] C. Lin, H. R. Chuang, and Y. C. Kan, "A 3-12 GHz UWB plan ar triangular monopole antenna with ridged groundplane," Progress In Electromagnetics Research, pp. 307- 321, 2008.

[9] Deng, Y. J. Xie, and P. Li, impedance bandwidth enhanced," pp. 1394-1397, Aug 2009.

[10] M. Dikmen, S. Cimen, and G. Cakr, "Planar octagonalshaped UWB antenna with reduced radar cross section," IEEE Transactions on Antennas and Propagation, pp. 2946293, June 2014.

[11] T.SyamKumar, V.SumaLatha and R.Samba Siva Nayak "Synchronization Enhancement to Network Processor Using IEEE 1588 Protocol" Proceedings of IEEE's International Conference on RF and Signal Processing Systems (RSPS), organized by K.L.University, Vaddeswaram, from $7-9^{\text {th }}$ January 2010,pp:385-389.

[12] R. Samba Siva Nayak, G.Ramana Reddy "Reconfigurable Antenna Array for Wireless LAN And WIMAX Applications", Published in the International Journal of emerging technologies and Applications in engineering, technology and sciences (IJ -ETA-ETS), ISSN: 0974-3588 July ' 12 - December '12 | Volume 5 : Issue 2 Page no :219220.

[13] R. Samba Siva Nayak, K. Suresh Babu "Reconfigurable Antenna Array Applications" Proceedings of International Conference on Systemics, Cybernetics and Informatics (ICSCI - 2011), organized by Hyderabad, from January 05 08, 2011.

[14] R. Samba Siva Nayak, Suman. J and Naveen "Analysis of Optical Soliton Propagation in Birefringent Fibers", Published in the International Journal of Management, IT and Engineering, (IJMRA), ISSN: 2249-0558 Volume-2, Issue-1, January 2012.

[15] R Samba Siva Nayak, Dr. R.P. Singh "Performance and Improvement of Various Antennas in Modern Wireless Communication System" International Journal of Advance Research in Science and Engineering, December 2017. ISSN: 2319-8354, Vol 6, Issue 4, Pages: 1164-1170.

[16] R Samba Siva Nayak, Dr. R. P. Singh “ A Brief Review on Performance of Antenna Designs in Modern Wireless Communication System (Paper Code: 01-2018-1974)" IEEE's International Conference on Electrical, Electronics, Computers, Communication, Mechanical and Computing ECCMC-2018), IEEE \& Priyadarshini Engineering College, Vellore Dist, Tamil Nadu, India, $27 \& 28^{\text {th }}$ January 2018.

[17] R. Sambasiva Nayak, R.P. Singh" Performance and Improvement of Antenna Designs in Modern Wireless Communication System" Journal of Microwave Engineering \& Technologies, ISSN: 2349-9001 (Online) Volume 4, Issue 3, 2017, and PP: 5-10.

[18] R Samba Siva Nayak, Dr R P Singh "Performance \& Improvement of Various Antenna Designs in Modern Wireless Communication System" International Journal of Creative Research Thoughts (IJCRT), March 2018, ISSN: 2320-2882, Vol 6 Issue 1 Pages: 1-6. 
[19] R. Sambasiva Nayak, Dr.R.P. Singh and Dr.M. Satya Sai Ram "Performance and Improvement of Various Antennas in Modern Wireless Communication System" Journal of Advanced Research in Dynamical and Control Systems" Volume: 10, Issue: 4, April 2018, Pages: 01-09.

[20] R Samba Siva Nayak, Dr. R.P. Singh "Performance and Improvement of Various Antennas in Modern Wireless Communication System" International Conference on Advance Studies in Engineering and Sciences (ICASES-17), Sri Satya Sai University of Technology \& Medical Sciences, Sehore, and Madhya Pradesh, India, $2^{\text {nd }}$ December 2017, ISBN: 978-93-86171-83-2, PP:1346-1352.

[21] R.Samba Siva Nayak, M.Manigandhan "Fourth Generation Wireless Communication Systems " proceedings of $2^{\text {nd }}$ National Conference on Information Sciences, organized by Manipal University, Manipal. 23-24 ${ }^{\text {th }}$ April 2010.

[22] T.Syamkumar, R.Samba Siva Nayak "A Security Solution for wireless local area Network", proceedings of National Conference on Signal Processing \& Communication Systems(NCSPCS2010), organized by RVR \& JC College of Engg., Guntur, from 25-26 ${ }^{\text {th }}$ February 2010,pp:60.

[23] R. Sambasiva Nayak, Dr.R.P. Singh, Dr.M. Satya Sai Ram, Dr. G.R. Selokar, Dr. Pushpendra Sharma, Dr.Sonal Bharti, Alka Thakur "RSS UWB Antenna for Contemporary Wireless Communication Systems" JASC: Journal of Applied Science and Computations, ISSN: 00765131, Volume 4, Issue 6, November /2017, ,pp:189-208.

[24] R. Sambasiva Nayak, Dr.R.P. Singh, Dr.M. Satya Sai Ram, Dr. G.R. Selokar,Dr. Pushpendra Sharma, Dr.Sonal Bharti, Alka Thakur "Beak-Shaped Monopole-Like Slot UWB Antenna for Modern Wireless Communication Systems IJR: International Journal of Research ,Volume 6, Issue XII, December/2017, ISSN: 2236-6124, Page No: 43-60.

[25] R. Sambasiva Nayak \& Dr. R. P. Singh "Performance and Improvement of Various Antennas in Modern Wireless Communication System" Global Journal of Computer Science and Technology: E Network, Web \& Security Type: Double Blind Peer Reviewed International Research Journal Publisher: Global Journals Online ISSN: 0975-4172\& Print ISSN: 0975-4350, Volume 18 Issue 1 Version 1.0 year 2018, pp: $27-30$.

[26] Praveen Kumar Pachala, R.Samba Siva Nayak, "GPS Based Vehicle Tracking System", proceedings of National Conference on Signal Processing \& Communication Systems (NCSPCS2010), organized by RVR \& JC College of Engg., Guntur, from 25-26 ${ }^{\text {th }}$ February 2010,pp:59.

[27] R.Samba Siva Nayak and M.V.S.Prasad "Wireless Mobile Online Applications using Frame work", proceedings of National Conference on Signal Processing \& Communication Systems(NCSPCS2010), organized by RVR \& JC College of Engg., Guntur, from 25-26 ${ }^{\text {th }}$ February 2010, pp:3.

[28] R.Samba Siva Nayak, Dr.M.S.Sairam "Runtime Reconfigurable Adaptive Viterbi Architecture " Proceedings of International Conference on Embedded Electronics and Computing Systems (EECS), organized by $\mathrm{S} K \mathrm{~K}$ Engineering College, Chennai, from 29-30 ${ }^{\text {th }}$ July, 2011.

\section{Authors}

R.Samba Siva Nayak is a Research Scholar in the Department of

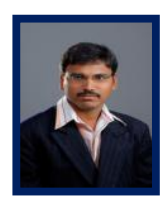
ECE at Sri Satya Sai University of Technology and Medical Sciences, Sehore, Madhya Pradesh. He has completed Graduated (B.Tech) in ECE from ANU, India and Post Graduated (M.Tech) in DECS from JNTUH, India. He has 15 years of teaching, research, and administrative experience. He has been active in research for more than 10 years and published more than 30 journals, 16 National \& 28 International Conferences in the field of Communications. He is a Member in IEEE, ISTE, IAENG, IACSIT, and UAECE \& Editorial Board Member etc. His research interests Antennas, Mobile/Cellular Systems, and Digital Image Processing.

Dr.R.P.Singh is former Director and Prof. Electronics and

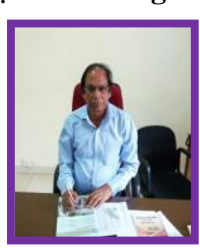
Communication at MANIT Bhopal. Dr. Singh $\mathrm{UG}$ and $\mathrm{PG}$ in Electronic Engineering from Institute of Technology (now IIT), B.H.U. Varanasi in 1971 and 1973, respectively. He did his Ph.D. from Barakatullah University Bhopal in 1991. He has 39 years of teaching, research, and administrative experience in MACT/MANIT out of which 22 years as Professor. He was Head of the Department at of Electronics, and Computer Science and Engineering Department at MANIT Bhopal from Jan 1996 to April 1998 and again during 2005-2008. He has worked as Professor Incharge Academic and Chairman Admission Committee Dean (Academic) \& Dean (R/D) at MACT /MANIT, Bhopal. He has published 125 papers in reputed and indexed Journals including SCI. He has authored two books in the area of Communication Engineering; one of these books is published by MP Hindi Granth Academy in Hindi and other in English by TMH. He has worked as Secretary, Chairman, IETE, M.P. and C.G. and Council Member, IETE. He was first Counselor of IEEE student's chapter at MACT, Bhopal. He has been member of Executive Committee, Institution of Engineers (I) M.P. Circle. He was Chairman of Computer Society of India. Bhopal. He was member of Board of Studies, and Research Degree committee of many Universities. He has chaired Technical Sessions of various National and International Conferences. He has been Consulting Editor of Journal of Institution of Engineers and reviewer in many Journals. Dr. Singh visited about 70 Institutions as an expert of NBA and about 35 Institutes as AICT/U G.C. expert team for approval.Twenty candidates have completed their Ph.D. under his supervision and another six are registered in the area of EC system and related disciplines. He has under taken several development/ research/ projects. Dr Singh has been identified as Leading Scientist of the World-2011 by International Centre, Cambridge England, and recognized as Distinguished Honorary Member to Research Board of Advisers, American Biographical Institutes (ABI) in 2003. One of his research paper was awarded Sir Thomas Ward Memorial Prize by IE. He has written Carrier Counseling Colum for Eng Education in Hindustan Times. He has been Member Board of Governs, M.A.N.I.T. and CRISP Bhopal. He has been Key Note Speaker, Guest of Honor, and Chief Guest in Conferences/ Seminars/ Workshop / Social gatherings.

Dr.M. Satya Sai Ram has 15 years of teaching, research, and

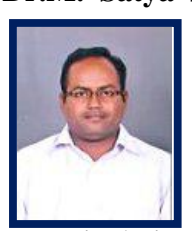
administrative experience as Professor. Obtained B.Tech degree and M.Tech degree from Nagarjuna University, Guntur. PhD from JNTUH, 2011. He has worked as Professor and HOD at Chalapathi Institute of Engineering and Technology, Chalapathi Nagar, Guntur, Andhra Pradesh, India. He actively involved in research and guiding for UG, PG AND PhD students in the area of ECE. He has taught a wide variety of courses for UG students and guided several projects. He has published 50 papers in National/International Conferences, Journals, and Scopus and indexed Journals including SCI. He is a Life Member in Indian Society for Technical Education, International Association of Engineers \& Editorial Board Member Also. His research interests Antennas, Mobile/Cellular Systems, and Signal Processing and VLSI etc. 